Editorial

\title{
Continuing challenges for learning disabled students
}

Volume I Issue 2 - 2014

\section{Ronald C Naso}

\section{Editorial}

It may come as a surprise to the readership that the 2004 legislative changes resulting in the Individuals with Disabilities Education Improvement Act (IDEIA) have made it increasingly difficult for learning disabled students to access services. A decade later, many of us who work with students from pre-K through college and beyond are finding that accommodations like extended time, computer use, and other assistive technologies previously available under the Americans with Disabilities Act (ADA) also have been curtailed. Students who previously enjoyed "extended time" on standardized tests now find their requests for this accommodation are being denied with increasing frequency. What has happened? Why are students who previously qualified under Individual with Disabilities Act unable to access necessary service?

The answer to this question is disturbing, but relatively straight forward: many school systems have failed to adopt this new standard and rely instead on the pre-2004 criteria. In brief, these criteria require both the diagnosis of a disability (or disabling condition) and a demonstration that the condition has a significant educational impact. While continued reliance on these criteria may be appropriate for decision regarding special educational services, it is problematic when applied to eligibility for accommodations. In 2009, the definition of the term "disability" was broadened in a way that lowered the threshold for receiving accommodations (Public Law, 110-32s). Previously, children with conditions like myopia, diabetes, asthma, and/or Attention Deficit-Hyperactivity Disorder (ADHD) qualified only if a significant education impact could be documented in spite of medical treatment. The new statue now requires school districts to consider these disabling conditions independent of the individual's response to intervention. Thus, a child treated with Adder all for ADHD meets the standard for a disability because a positive response to medication can no longer be used to disqualify him.

More than ever, careful psychological evaluation will be necessary to demonstrate the presence of "significant" and "substantial"
American Board and Academy of Psychoanalysis, USA

Correspondence: Ronald C Naso,American Board and Academy of Psychoanalysis, 2777 Summer Street, Suite 504B, Stamford, CT 06905, USA, Tel 203-325-366I, Fax 203-325-0I45, Email rcnphd@gmail.com

Received: June 18,2014 | Published: June 19, 2014

disabilities. Specifically, this will require that psychologists are familiar with the language of these statues in order to effectively assist families in their efforts to navigate what often is a daunting qualification process in order to receive the services so many children desperately need. It also means that physicians will be asked to play a greater role in documenting these conditions and identifying their impact on learning. In a time of economic uncertainty, these changes are a welcome opportunity to help children and young adults develop the skills they will need to be happy, healthy, and productive adults.

\section{Acknowledgments}

None.

\section{Conflicts of interest}

Author declares there are no conflicts of interest.

\section{Funding}

None. 